\title{
KEPUASAN WISATAWAN DALAM PENGGUNAAN E-COMMERCE AGODA DALAM PEMESANAN HOTEL
}

\author{
Suci Sandi Wachyuni ${ }^{1,2 *}$, Kadek Wiweka ${ }^{1,3,4}$ \\ Politeknik Sahid ${ }^{1}$ \\ Program Doktor Kajian Pariwisata, Sekolah Pascasarjana Universitas Gadjah Mada² \\ École Doctorale Sociétés, Temps, Territoires Université Angers, France ${ }^{3}$; \\ ITRC (Indonesia Tourism Research Consultant) ${ }^{4}$ \\ * sucisandi@stpsahid.ac.id
}

\begin{abstract}
The industrial revolution that entered the 4.0 phase encouraged the industry to innovate, where one of the developing industries was e-commerce. As part of the online travel agents (OTA), Agoda through its e-commerce offers not only products but also services. However, at the moment, referring to the 2019 top brand awards ranking, Agoda can be said to be left behind. Therefore, this research intends to examine the satisfaction of tourists (consumers) in using Agoda for booking hotels. This research is based on descriptive quantitative approach, where primary data is collected through questionnaire with indicators of customer satisfaction (Repurchase, Emotional Factor, Word of Mouth, Price, Brand Image, Service Quality, and Product Quality). The scale used is Likert scale (1-5), and the sampling method used is probability sampling, which is simple random sampling with a total of a hundred respondents. The secondary data is taken from Agoda's website, books, literature, and previous research. The study was conducted during June-July 2019. This study found that the average tourist was quite satisfied with Agoda's services in booking hotels. However, to maintain its existence, Agoda needs to make efforts to attract tourists, especially in improving the Agoda brand image. Also, the cooperation partners, which are hotels, will have high confidence in marketing their hotels through Agoda. Furthermore, in terms of the marketing segment, Agoda is very firmly attached to the millennial generation in meeting accommodation needs. However, it is interesting to investigate further the purpose of booking this accommodation, whether for travel needs or other vacation concepts, like one of the popular concepts nowadays, "staycation". This research is expected to provide information about service conditions and customer satisfaction using Agoda. The findings of this study can be useful not only for Agoda companies but also for other OTAs who offer similar products or services.
\end{abstract}

Keywords: tourist satisfaction, e-commerce, pemesanan hotel, online travel agent (OTA)

\begin{abstract}
Abstrak
Revolusi industri yang memasuki fase 4.0 mendorong industri untuk berinovasi, di mana salah satu industri yang berkembang adalah e-commerce. Sebagai bagian dari agen perjalanan online (OTA), Agoda melalui perdagangan elektronik tidak hanya menawarkan produk tetapi juga layanan. Namun, saat ini, mengacu pada peringkat penghargaan merek teratas 2019, Agoda dapat dikatakan tertinggal. Oleh karena itu, penelitian ini bermaksud untuk menguji kepuasan wisatawan (konsumen) dalam menggunakan Agoda untuk pemesanan hotel. Penelitian ini didasarkan pada pendekatan deskriptif kuantitatif, di mana data primer dikumpulkan melalui kuesioner dengan indikator kepuasan pelanggan (Pembelian Kembali, Faktor Emosional, dari mulut ke mulut, Harga, Citra Merek, Kualitas Layanan, dan Kualitas Produk). Skala yang digunakan adalah skala likert (1-5), dan metode pengambilan sampel yang digunakan adalah pengambilan sampel probabilitas, yaitu contoh acak sederhana dengan total seratus responden. Data sekunder diambil dari situs web Agoda, buku, literatur, dan penelitian sebelumnya. Studi ini dilakukan selama Juni-Juli 2019. Studi ini menemukan bahwa rata-rata turis cukup puas dengan layanan Agoda dalam memesan hotel. Namun, untuk mempertahankan keberadaannya, Agoda perlu melakukan upaya untuk menarik wisatawan, terutama dalam meningkatkan citra merek Agoda. Juga, mitra kerja sama,
\end{abstract}


yang merupakan hotel, akan memiliki kepercayaan diri yang tinggi dalam memasarkan hotel mereka melalui Agoda. Selain itu, dalam hal segmen pemasaran, Agoda sangat terikat dengan generasi milenial dalam memenuhi kebutuhan akomodasi. Namun, menarik untuk menyelidiki lebih lanjut tujuan pemesanan akomodasi ini, baik untuk kebutuhan perjalanan atau konsep liburan lainnya, seperti salah satu konsep populer saat ini, "staycation". Penelitian ini diharapkan dapat memberikan informasi tentang kondisi layanan dan kepuasan pelanggan menggunakan Agoda. Temuan penelitian ini dapat bermanfaat tidak hanya untuk perusahaan Agoda tetapi juga untuk OTA lain yang menawarkan produk atau layanan serupa. Kata kunci: kepuasan wisatawan, perdagangan elektronik, pemesanan hotel, online travel agent (OTA)

\section{PENDAHULUAN}

Revolusi industri yang masuk kepada fase 4.0 mendorong industri melakukan inovasi dari berbagai sisi, mulai dari metode memperkenalkan produk, hingga pengembangan produk atau jasa itu sendiri. Pariwisata merupakan salah satu industri yang mengalami evolusi dari konvensional menjadi lebih modern. Fenomena ini dipengaruhi oleh permintaan pasar yang didominasi oleh generasi milenial (Setiawan dkk., 2018; Wiweka dkk., 2019), yang memiliki karakteristik "unik" atau memiliki kecenderungan terhadap teknologi. Generasi yang biasa dikenal dengan generasi $\mathrm{Z}$ terbiasa menggunakan teknologi pada sebagian besar aktivitasnya, termasuk berwisata. Salah satu media yang dikenal cukup familiar dengan generasi ini adalah sosial media (Damanik dkk., 2019). Dampaknya berbagai industri, mulai dari transportasi (Kusmayadi et al., 2019) hingga akomodasi (Wachyuni dkk., 2018) melakukan inovasi pada pelayanan mereka, termasuk pada saluran distribusi (pemesanan) yang berbasis media sosial. Saluran atau jalur distribusi digital (Mulhern, 2009; Lipiäinen, 2014) saat ini sangat marak diimplementasikan oleh berbagai industri pariwisata, fenomena ini membuat pemasaran semakin kompleks, terintegrasi (Rakić \& Rakić, 2014) dan cenderung tumbuh sangat pesat. Tren ini dikenal dengan istilah pemasaran digital atau E-Commerce.

Menurut Karyatiningsih (2011), e-commerce adalah teknik pemasaran yang terdiri dari penawaran, penjualan, hingga pembelian, baik produk, jasa, maupun informasi berbasis media elektronik atau dengan memaksimalkan peran jejaring internet. Teknik ini telah menciptakan ekosistem bisnis baru antara penjual dan pembeli dengan perantara media elektronik atau berbasis teknologi. Di Indonesia perkembangan transaksi ini telah begitu pesat yang didukung oleh berbagai startups, salah satunya OTA (online travel agent). OTA sendiri tumbuh di tengah perkembangan teknologi yang pesat, hingga akhirnya menggeser eksistensi agen perjalanan konvensional yang tidak berbasis digital atau teknologi (Mulhern, 2009). Jannah (207) berpendapat bahwa Online Travel Agent merupakan layanan berbasis online melalui website yang seluruh kegiatan produksinya dilakukan seluruhnya secara real time. Online Travel Agent merupakan alat komunikasi paling efektif yang menghubungkan wisatawan dengan properti seperti hotel-hotel di seluruh mancanegara. Beberapa Online Travel Agent yang banyak diminati oleh wisatawan yaitu traveloka, booking.com., agoda, tiket.com., dan trivago. Beberapa OTA tersebut di Indonesia telah mendapatkan pengakuan sebagai top brand, yang diantaranya

Tabel 1. OTA penyedia layanan On-line Booking

\begin{tabular}{|l|c|c|}
\hline \multicolumn{1}{|c|}{ MEREK } & RATE & TOP \\
\hline Traveloka.com & $45,7 \%$ & TOP \\
\hline Trivago.co.id & $6,5 \%$ & TOP \\
\hline Pegipegi.com & $3,1 \%$ & \\
\hline Tiket.com & $2,8 \%$ & \\
\hline Agoda.com & $2,3 \%$ & \\
\hline
\end{tabular}

Sumber: (Top Brand Index Beserta Kategori

Lengkap Top Brand Award, n.d, 2018)

Tabel 1 menunjukan bahwa Traveloka dan Trivago mendominasi sebagai top brand di Indonesia, sedangkan Agoda mendapat perolehan terendah dari kategori Situs Online Booking Tiket Pesawat dan Travel berdasarkan Top Brand Award 2018. Fenomena ini tentu sangat menarik untuk dikaji dimana secara sekilas seluruh OTA tersebut menawarkan produk yang hampir serupa. Namun seperti sebagian besar karakteristik 
industri pariwisata, bahwa produk bukan satusatunya penentu ketertarikan konsumen, namun jasa atau pelayanan bahkan cenderung lebih menentukan eksistensi produk tersebut. Oleh karenanya penelitian ini ingin mengkaji tentang pelayanan yang diberikan oleh Agoda.com. Adapun kepuasan konsumen merupakan fokus utama dari penelitian ini, khususya saat memanfaatkan jasa OTA tersebut. Meskipun bukan satu-satunya penelitian yang mengkaji Agoda (Octavia \& Tamerlane, 2017; Oktavianus, 2014; Pitchayadejanant dkk., 2019; Sindunata \& Wahyudi, 2018), namun kajian ini diangap masih relevan dengan kondisi terkini, terutama melihat peringkat top brand awards di atas. Kusumaningrum dkk. (2019) berpendapat bahwa kepuasan konsumen dapat digunakan sebagai pedoman dalam memahami standar nilai atau kualitas sebuah produk atau jasa. Kepuasan ini juga dapat diukur sehingga jasa yang cenderung bersifat abstrak menjadi lebih "nyata" meskipun belum tentu menggambarkan pelayanannya secara utuh. Sunyoto (2013) berpendapat bahwa pengukuran atau pemantauan kepuasan pelanggan merupakan salah satu elemen yang penting, terutama bagi perusahaan dalam memahami minat dan respon konsumen dalam menggunakan kembali produk maupun jasa yang mereka gunakan. Proses ini juga memerlukan pendekatan yang sistematis dan komprehensif, mengingat kepuasan pelanggan dibentuk dari berbagai faktor yang kompleks. Adapun metode-metode yang mungkin diadopsi dalam menganalisa tingkat kepuasan konsumen diantaranya di antaranya melalui komentar dan masukan, jasa Ghost Shopping, analisis mantan pelanggan, dan survei kepuasan pelanggan.

Analisis ini dilakukan dengan tujuan utama untuk mempertahankan konsumen, dimana menurut (Kotler \& Keller, 2009), kepuasan pelanggan menjadi faktor krusial dalam usaha perusahaan untuk mempertahankan konsumen. Ia menjabarkan beberapa faktor-faktor yang umumnya dapat dikenal sebagai pembentuk kepuasan pelanggan, di antaranya:

\section{Re-purchase}

Secara sederhana, pembelian kembali suatu produk atau jasa oleh konsumen dapat dikategorikan pembelian ulang. Lu dkk (2016) dalam penelitiannya menyatakan bahwa salah satu faktor yang menentukan wisatawan atau konsumen datang membeli kembali adalah kepercayaan. Kepercayaan wisatawan akan suatu tempat wisata dipercaya akan meningkatkan keinginan wisatawan untuk membeli kembali atau berkunjung ke suatu destinasi. Indikator ini juga telah banyak digunakan oleh berbagai penelitian yang terkait dengan digital marketing atau pemasaran digital (Dadang, 2016).

\section{Word of mouth}

Meskipun dikenal sebagai faktor yang cukup konvensional atau klasik, namun peran WOM hingga saat ini masih dipercaya sebagai faktor yang sangat efektif dalam mempengaruhi konsumen yang lain, baik bagi konsumen yang merasa puas ataupun sebaliknya. Word of mouth (WOM) umumnya merupakan respon dari pengalaman konsumen selama menikmati atau menggunakan suatu produk atau jasa, secara spesifik dapat berupa komentar atau rekomendasi. Seperti yang telah disampaikan sebelumnya, faktor ini memiliki pengaruh yang kuat terhadap pengambilan keputusan yang dilakukan oleh pihak lain. Dalam perkembangannya WOM ini telah bertransformasi dan dikenal sebagai EWOM (Electronic Word of Mouth) yang dipengaruhi oleh perkembangan dunia digital (Jalilvand \& Samiei, 2012; Phillips et al., 2013; Sindunata \& Wahyudi, 2018, 2018).

\section{Brand Image}

Loyalitas konsumen nyatanya tidak hanya dipengaruhi oleh faktor eksternal dari produk atau jasa, namun juga kerap dipengaruhi faktor internal, salah staunya merek atau citra. Dewanti dkk, (2007) menyatakan bahwa salah satu faktor dalam persaingan dalam suatu industri adalah brand image atau reputasi yang dimiliki oleh industri itu sendiri. Ia menambahkan bahwa brand image suatu industri dapat diraih melalui proses yang panjang dan kompleks. Sedangkan Hidayah (2013) berpendapat bahwa sebuah brand ditentukan oleh berbagai strategi yang diterapkan oleh suatu perusahan, mulai dari pembentukan suatu produk, hingga stratgei pemasaran lainnya, seperti segmentasi pasar, menentukan target, hingga memposisikan produk yang mereka miliki. Satu kesatuan strategi tersebut menciptakan karakteristik 
produk tersendiri yang mungkin berbeda dengan produk atau jasa yang lain. Karakteristik tersebut akhirnya menjadi identitas yang membentuk brand image. Oleh karenanya, identitas tersebut dipercaya tidak hanya akan menjadi kuat bila hanya melalui satu strategi, seperti mengiklankan di media massa atau publisitas. Adapun Nursanti dkk (2009) dan Hariyani \& Sartana (2014) berpandangan bahwa brand image adalah adanya karakteristik sejumlah asosiasi yang menimbulkan kesatuan arti, yang pada akhirnya kesatuan arti tersebut menentukan reaksi konsumen secara terpadu dalam memberikan penilaian atau tanggapan terhadap suatu merek ( $b$ rand). Ia juga mencatat bahwa merek berfungsi memilik berbagai fungsi, diantaranya mengumpulkan informasi (retrieve information), memberikan karakter atau pembeda (differentiate), (reason to buy), menciptakan perasaan yang positif (create positive attitudeffeelings), meningkatkan kepekaan konsumen terutama terkait dengan brand association atau manfaat bagi konsumen (customer benefit), memunculkan rasa kesesuaian (sense of fit in) antara brand dengan sebuah produk, hingga memberikan alasan untuk membeli produk (basis for extension). Secara umum dapat dikatakan bahwa brand image memiliki peran dalam mempengaruhi kepuasan pelanggan (Hidayah, 2013).

\section{Product Quality}

Kualitas produk merupakan suatu produk yang sesuai dengan apa yang diharapkan oleh konsumen. Dengan kualitas produk yang baik, pelanggan akan merasa puas dan akan melakukan transaksi ulang kepada perusahaan penyedia jasa/produk tersebut (Octavia \& Tamerlane, 2017).

\section{Price}

Harga adalah sejumlah nilai yang dipertukarkan untuk memperoleh suatu produk bagi pelanggan yang sensitif biasanya harga murah adalah sumber kepuasan yang penting karena mereka akan mendapatkan value for money yang tinggi. Dengan kata lain, harga adalah sejumlah uang yang konsumen bayar untuk membeli produk atau mengganti hal milik produk. Harga meliputi last price, discount, allowance, payment period, credit terms, dan retail price.

\section{Service Quality}

Jika jasa yang diterima oleh konsumen dirasakan sesuai dengan yang diharapkan, maka kualitas pelayanan dipersepsikan baik dan memuaskan, jika jasa yang diterima melampaui harapan konsumen, maka kualitas pelayanan dipersepsikan sangat baik dan berkualitas. Sebaliknya apabila jasa yang diterima tidak sesuai ekspektasi pelanggan maka kualitas pelayanan dipersepsikan buruk. Dalam kasus ini jasa atau pelayanan yang diberikan oleh e-commerce dipercaya dapat mempengaruhi kepuasan pengguna OTA (Ali \& Howaidee, 2012; Cox \& Dale, 2001; Dedeke, 2016, 2016; Ho \& Lee, 2007; Pitchayadejanant dkk., 2019).

\section{Emotional Factor}

Faktor emosional merupakan faktor yang berhubungan dengan gaya hidup seseorang. Emosi merupakan perasaan bergejolak yang berpengaruh langsung terhadap kepuasan pelanggan. Faktor ini dipercaya memainkan peran yang cukup penting dalam menentukan kepuasan pelanggan terutama dalam bidang jasa $(e-$ commerce) (Chang, 2008; Prayag dkk., 2017).

Ketujuh indikator ini kemudian dijadikan dasar penilaian kepuasan pelanggan dalam penggunaan E-Commerce Agoda dalam pembelian voucher hotel. Kajian ini bertujuan untuk memberikan informasi terkait kondisi pelayanan dan kepuasan pelanggan yang menggunakan Agoda. Sehingga hasil penelitian ini diharapkan berguna bagi OTA lain yang menawarkan produk atau jasa serupa, dan tidak terbatas pada perusahaan Agoda.

\section{METODE}

Metode yang digunakan dalam penelitian ini adalah metode deskriptif kuantitatif. Data Primer dikumpulkan dari kuesioner tentang kepuasan pelanggan dengan indikator Repurchase, Word of Mouth, Brand Image, Product Quality, Price, Service Quality, dan Emotional Factor dihitung berdasarkan skala likert (1-5). Teknik sampling yang digunakan adalah probability sampling yaitu simple random sampling dengan jumlah responden sebanyak 100 orang. Menurut Hair Jr dkk. (2016) umumnya 
dalam menganalisis faktor membutuhkan minimal 100 orang responden. Sedangkan data sekunder diambil dari website Agoda, buku, literatur, dan penelitian sebelumnya. Penelitian dilakukan selama Juni-Juli tahun 2019. Teknik analisis data menggunakan analisis deskriptif kuantitatif. Menurut Sugiyono (2003), penelitian kuantitatif merupakan penelitian dengan menggunakan data angka untuk diolah kemudian diinterpretasikan.

\section{HASIL DAN PEMBAHASAN Profil Agoda}

Agoda adalah perusahaan internet yang menyediakan layanan reservasi properti hotel atau resor secara online yang difokuskan terutama pada kawasan Asia Pasifik dengan basis operasional yang berada di Bangkok, Singapura, dan Filipina.
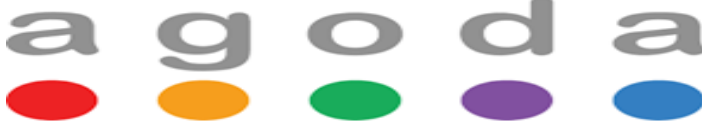

Gambar 1. Logo Agoda

Agoda didirikan oleh Michael Kenny pada akhir tahun 1990 dengan nama Planetholiday.com. Pengguna dapat menggunakan ketersediaan layanan Agoda yang dilayani dalam 21 bahasa antara lain bahasa Indonesia, China, Inggris, Perancis, Spanyol, Jepang dan Thailand. Kantor pusat Agoda terletak di Bangkok, Singapura dan Filipina.

\section{Profil dan Karakteristik Responden Pengguna Agoda}

Berdasarkan hasil survey profil dan karakteristik responden, mayoritas responden dalam penelitian ini $51 \%$ berjenis kelamin perempuan dan $49 \%$ laki-laki. Berdasarkan usia, responden didominasi usia 21-25 tahun sebanyak 74\%, diikuti oleh $11 \%$ berusia 26-30 tahun, 8\% berusia 15-20 tahun dan $7 \%$ berusia lebih dari 30 tahun. Mayoritas responden berdomisili di Jakarta sebesar 76\%, diikuti Bali 11\%, Bandung 7\%, dan Medan 5\%. Responden dengan latar pendidikan terakhir S1 sebanyak 56\%, diikuti oleh $41 \%$ SMA, $1 \%$ Diploma 4, dan 1\% SD. Penggunaan Agoda didominasi oleh pelajar sebanyak 55\%, 21\% karyawan, 16\% wiraswasta, 7\% Manajer, 2\% lainnya menyebutkan Disc Jockey (DJ). Penghasilan rata-rata tertinggi sebesar 55\% dengan rentang Rp1.000.000 - Rp5.000.000, diikuti dengan 24\% berpenghasilan Rp5.000.000 - Rp10.000.000, 11\% berpenghasilan Rp10.000.000 - Rp15.000.000. Pemesanan hotel melalui agoda sebesar 57\% responden memilih akomodasi dengan rentang harga Rp500.000 - Rp1.000.000, sebesar 28\% memilih hotel pada rentang harga Rp 1.000.000-Rp 2.000.000, $7 \%$ hotel dengan harga Rp2.000.000-Rp3.000.000, dan $8 \%$ lainnya memilih hotel dengan harga lebih dari Rp3.000.000. Media elektronik/gadget yang paling banyak digunakan dalam melakukan pemesanan adalah smartphone sebesar $97 \%$. 1\% menggunakan tablet, $1 \%$ menggunakan komputer (PC), dan $1 \%$ lainnya menggunakan laptop.

Data profil responden dapat dilihat Pada Tabel 1. Dari data tersebut, terlihat pembelian melalui agoda didominasi oleh generasi milenial yang lahir pada tahun 1981-2000. Milenial sangat fasih dalam menggunakan teknologi. Mereka menggunakannya bukan hanya untuk bersosialisasi, bahkan beramal, dan melakukan pembelian. Milenial juga menggunakan media untuk menjadi konsumen yang berpengetahuan tentang merk dan apapun yang mereka gemari (Vinick dan Abbott, 2015). Penggunaan smartphone menjadi yang paling favorit dikarenakan paling praktis dapat diakses dimanapun dan kapanpun dibandingkan dengan gadget lainnya.

\section{Tabel 1. Profil dan Karakteristik Responden}

\begin{tabular}{|l|l|r|}
\hline Indikator & \multicolumn{1}{|c|}{ Opsional } & $\begin{array}{r}\text { Persentase } \\
(\%)\end{array}$ \\
\hline \hline \multirow{4}{*}{$\begin{array}{l}\text { Jenis } \\
\text { Kelamin }\end{array}$} & Laki-Laki & 49,00 \\
\cline { 2 - 3 } & Perempuan & 51,00 \\
\hline \multirow{5}{*}{ Usia } & $15-20$ tahun & 8,00 \\
\cline { 2 - 3 } & $21-25$ tahun & 74,00 \\
\cline { 2 - 3 } & $26-30$ tahun & 11,00 \\
\cline { 2 - 3 } & $>30$ tahun & 7,00 \\
\hline \multirow{5}{*}{ Domisili } & Jakarta & 76,00 \\
\cline { 2 - 3 } & Bali & 11,00 \\
\cline { 2 - 3 } & Bandung & 5,00 \\
\cline { 2 - 3 } & Medan & 5,00 \\
\cline { 2 - 3 } & Lampung & 0,00 \\
\cline { 2 - 3 } & Tangerang & 2,00 \\
\cline { 2 - 3 } & China & 1,00 \\
\hline \multirow{3}{*}{$\begin{array}{l}\text { Pendidikan } \\
\text { Terakhir }\end{array}$} & SD & 1,00 \\
\cline { 2 - 3 } & SMP & 0,00 \\
\hline
\end{tabular}




\begin{tabular}{|c|c|c|}
\hline Indikator & Opsional & \begin{tabular}{|c} 
Persentase \\
$(\%)$
\end{tabular} \\
\hline & SMA & 41,00 \\
\hline & S1 & 56,00 \\
\hline & $\mathrm{S} 2$ & 0,00 \\
\hline & D3 & 1,00 \\
\hline & D4 & 1,00 \\
\hline \multirow{6}{*}{ Pekerjaan } & Pelajar/Mahasiswa & 55,00 \\
\hline & Karyawan & 21,00 \\
\hline & Wiraswasta & 16,00 \\
\hline & Manager/Eksekutif & 7,00 \\
\hline & Tidak Bekerja & 0,00 \\
\hline & DJ & 2,00 \\
\hline \multirow{4}{*}{$\begin{array}{l}\text { Penghasilan } \\
\text { Rata-Rata }\end{array}$} & Rp. 1.000.000 - Rp. 5.000 .000 & 55,00 \\
\hline & Rp. 5.000.000 - Rp. 10.000 .000 & 24,00 \\
\hline & Rp. 10.000 .000 - Rp. 15.000 .000 & 11,00 \\
\hline & > Rp. 15.000 .000 & 10,00 \\
\hline \multirow{4}{*}{$\begin{array}{l}\text { Biaya } \\
\text { Akomodasi }\end{array}$} & Rp. 500.000 - Rp. 1.000 .000 & 57,00 \\
\hline & Rp. 1.000 .000 - Rp 2.000 .000 & 28,00 \\
\hline & Rp. 2.000 .000 - Rp. 3.000 .000 & 7,00 \\
\hline & $>$ Rp. 3.000.000 & 8,00 \\
\hline \multirow{4}{*}{ Gadget } & Smartphone & 97,00 \\
\hline & Tablet & 1,00 \\
\hline & $\mathrm{PC}$ & 1,00 \\
\hline & Laptop & 1,00 \\
\hline
\end{tabular}

Kepuasan Pengguna Agoda dalam Pembelian Kamar Hotel di ukur dengan indikator (Kotler \& Keller, 2009), yaitu re-purchase, word of mouth, brand image, product quality, price, service quality, dan emotional factor. Data rekapitulasi kepuasan pelanggan terhadap layanan Agoda dapat dilihat pada Tabel 2.

Tabel 2. Data rekapitulasi kepuasan pelanggan Agoda

\begin{tabular}{|c|c|l|c|}
\hline Variabel & Indikator & \multicolumn{1}{|c|}{ Keterangan } & Mean \\
\hline \hline \multirow{2}{*}{$\begin{array}{l}\text { Kepuasan } \\
\text { Pelanggan }\end{array}$} & \multirow{2}{*}{ Re-purchase } & $\begin{array}{l}\text { Saya akan membeli } \\
\text { ulang voucher hotel } \\
\text { melalui situs Agoda }\end{array}$ & 3,54 \\
\cline { 3 - 4 } & $\begin{array}{l}\text { Situs Agoda memberikan } \\
\text { kepercayaan lebih } \\
\text { dibandingkan e-commerce } \\
\text { lain dalam pembelian } \\
\text { voucher hotel }\end{array}$ & 3,48 \\
\cline { 2 - 4 } & Total Mean & $\mathbf{3 , 5 1}$ \\
\hline
\end{tabular}

\begin{tabular}{|c|c|c|c|}
\hline Variabel & Indikator & Keterangan & Mean \\
\hline & \multirow{3}{*}{$\begin{array}{l}\text { Word of } \\
\text { Mouth }\end{array}$} & $\begin{array}{l}\text { Saya mendengar hal } \\
\text { positif tentang situs } \\
\text { Agoda dari orang lain }\end{array}$ & 3,54 \\
\hline & & $\begin{array}{l}\text { Saya akan } \\
\text { merekomendasikan } \\
\text { Agoda kepada orang } \\
\text { lain }\end{array}$ & 3,43 \\
\hline & & Total Mean & 3,48 \\
\hline & \multirow{3}{*}{$\begin{array}{l}\text { Brand } \\
\text { Image }\end{array}$} & $\begin{array}{l}\text { Saya langsung } \\
\text { mengingat Agoda } \\
\text { ketika ingin membeli } \\
\text { voucher hotel }\end{array}$ & 3,24 \\
\hline & & $\begin{array}{l}\text { Saya lebih memilih } \\
\text { Agoda dibandingkan } \\
\text { dengan brand lain } \\
\text { untuk membeli voucher } \\
\text { hotel }\end{array}$ & 3,18 \\
\hline & & Total Mean & 3,21 \\
\hline & \multirow{3}{*}{$\begin{array}{l}\text { Product } \\
\text { Quality }\end{array}$} & $\begin{array}{l}\text { Kualitas produk yang } \\
\text { ditawarkan oleh Agoda } \\
\text { sesuai dengan harga } \\
\end{array}$ & 3,64 \\
\hline & & $\begin{array}{l}\text { Situs Agoda } \\
\text { memberikan pilihan } \\
\text { hotel yang beragam dan } \\
\text { berkualitas } \\
\end{array}$ & 3,70 \\
\hline & & Total Mean & 3,67 \\
\hline & \multirow{3}{*}{ Price } & $\begin{array}{l}\text { Situs Agoda } \\
\text { menawarkan harga } \\
\text { terbaik }\end{array}$ & 3,43 \\
\hline & & $\begin{array}{l}\text { Harga voucher hotel di } \\
\text { Agoda cenderung lebih } \\
\text { murah dibandingkan } \\
\text { dengan situs lainnya }\end{array}$ & 3,52 \\
\hline & & Total Mean & 3,47 \\
\hline & \multirow{3}{*}{$\begin{array}{l}\text { Service } \\
\text { Quality }\end{array}$} & $\begin{array}{l}\text { Situs Agoda } \\
\text { memberikan informasi } \\
\text { yang jelas mengenai } \\
\text { harga, lokasi, dan } \\
\text { gambar hotel } \\
\end{array}$ & 3,70 \\
\hline & & $\begin{array}{l}\text { Agoda menyediakan } \\
\text { beragam metode } \\
\text { pembayaran }\end{array}$ & 3,63 \\
\hline & & Total Mean & 3,67 \\
\hline & \multirow{3}{*}{$\begin{array}{c}\text { Emotional } \\
\text { Factor }\end{array}$} & $\begin{array}{l}\text { Informasi data yang } \\
\text { saya berikan terjaga } \\
\text { dengan baik }\end{array}$ & 3,70 \\
\hline & & $\begin{array}{l}\text { Saya merasa nyaman } \\
\text { dalam menggunakan } \\
\text { Agoda dalam } \\
\text { pembelian voucher } \\
\text { hotel }\end{array}$ & 3,58 \\
\hline & & Total Mean & 3,64 \\
\hline
\end{tabular}


Dari beberapa indikator kepuasan pelanggan, rata-rata pelanggan menilai cukup puas hingga puas dengan layanan yang diberikan oleh Agoda. Nilai rata-rata tertinggi terletak pada indikator Product Quality dan Service Quality yaitu 3,67 yang berarti puas terhadap produk serta layanan yang diberikan oleh Agoda. Agoda memberikan pilihan hotel yang berkualitas sesuai dengan harga yang ditawarkan. Dalam segi layanan, Agoda memberikan informasi yang jelas kepada pelanggan dan memberikan kemudahan berupa metode pembayaran yang beragam. Kualitas layanan yang sesuai dengan harapan pelanggan merupakan indikator penting dalam kepuasan pelanggan, seperti pada penelitian Wachyuni (2019), variabel kualitas layanan berkorelasi positif dengan kepuasan pelanggan.

Selanjutnya, pada indikator emotional factor, rata-rata pelanggan menyatakan puas terhadap layanan yang diberikan karena data-data pelanggan terjaga kerahasiaannya. Pelanggan rata-rata juga menyatakan nyaman dalam menggunakan agoda sebagai platform dalam memesan hotel, sehingga pelanggan akan melakukan pembelian ulang (re-purchase) pada situs agoda untuk pemenuhan kebutuhan akomodasi. Pada pernyataan kuisioner tentang kepercayaan yang lebih pada situs agoda dibanding situs lainnya, rata-rata responden menjawab cukup setuju, sehingga agoda menjadi salah satu situs yang cukup dipertimbangkan sebagai layanan e-commerce penjualan jasa akomodasi. Pada indikator word-of-mouth, rata-rata pelanggan mendengar kesan positif mengenai agoda dari orang lain dan cukup setuju untuk merekomendasikan agoda. Pelanggan juga cukup setuju bahwa harga yang ditawarkan oleh agoda adalah harga terbaik dan kompetitif dibandingkan situs lainnya. Rerata nilai terendah dari tujuh indikator kepuasan pelanggan terletak pada indikator brand image, dimana pelanggan menyatakan cukup setuju jika ingin melakukan pemesanan hotel yang pertama kali muncul di benak pelanggan adalah agoda. Berarti dalam hal ini, masih ada situs lain yang lebih diingat oleh responden. Menurut Kotler \& Keller (2009), brand image merupakan citra merek yang kuat yang diberikan oleh perusahaan yang dapat membantu loyalitas pelanggan. Untuk itu, agoda harus meningkatkan nilai kompetitif di antara situssitus penyedia layanan sejenis lainnya agar meningkatkan kekuatan merek.
Menurut Wachyuni (2019) kepuasan merupakan harapan pelanggan pada sebuah kepercayaan mengenai produk atau jasa yang berguna sebagai acuan dan sebagai perbandingan standar terhadap nilai produk atau jasa tersebut. Kotler \& Keller (2009) menyatakan kunci untuk mempertahankan pelanggan adalah kepuasan pelanggan. Kepuasan pelanggan dapat dilihat dari kegiatan pembelian ulang yang dilakukan konsumen, pelanggan yang merasa puas dan mengatakan hal-hal baik tentang perusahaan kepada orang lain, citra merek yang dapat membangun loyalitas pelanggan, kualitas produk yang baik, value for money yang tinggi, dan jika jasa yang diterima oleh konsumen dirasa sesuai dengan yang diharapkan. Oleh karena itu, untuk memberikan kepuasan pelanggan yang lebih hingga mencapai loyalitas, Agoda perlu melakukan upaya-upaya seperti branding dan promosi agar merebut posisi prioritas situs pemesanan hotel secara online.

Branding dapat dilakukan dengan mengoptimalkan search engine/mesin pencari seperti Google, Yahoo, dan lainnya untuk memposisikan Agoda dalam rangking pertama di hasil mesin pencarian. Dalam penelitian eksperimen yang dilakukan oleh Dou dkk. (2010), suatu merek tidak ternama ditampilkan di posisi pertama diikuti dengan beberapa merk ternama dalam satu laman hasil pencarian memberikan kesan merek yang lebih diakui terutama pada pencari dengan skill pencarian rendah. Lebih lanjut, pada penelitian tersebut dijelaskan bahwa pencarian dengan menggunakan mesin pencari menjadi alat yang sangat bermakna dalam membentuk posisi merek pada e-commerce. Perusahaan dapat melakukan optimasi marketing dengan menggunakan mesin pencari dengan mudah dan tanpa biaya.

Brand image yang baik bukan hanya berpengaruh terhadap pelanggan agoda, namun dari segi mitra yakni hotel yang bekerjasama dengan agoda juga akan memiliki kepercayaan yang lebih tinggi untuk memasarkan hotelnya. Online Travel Agent (OTA) dianggap sebagai alat pemasaran yang efektif, hal ini sesuai dengan penelitian yang dilakukan oleh Wachyuni dkk. (2018) bahwa OTA sangat efektif dalam meningkatkan penjualan di hotel. Pada hasil penelitiannya, pendapatan yang diterima hotel dreamtel yang menjadi obyek penelitian, meraih lebih banyak pendapatan melalui OTA dibandingkan dengan walk in guest. Sehingga, kepercayaan kepada Agoda harus terus dibangun, baik dari sisi pelanggan maupun dari sisi mitra kerjasama. 


\section{KESIMPULAN}

Berdasarkan hasil penelitian, rata-rata wisatawan cukup puas hingga puas dengan layanan Agoda dalam pemesanan hotel. Untuk menjaga eksistensinya, Agoda perlu melakukan upaya untuk menarik wisatawan terutama dalam meningkatkan brand image agoda. Peningkatan citra merek dan promosi diperlukan agar menjadi prioritas online travel agent yang diandalkan wisatawan. Selain itu, mitra kerjasama yakni hotel juga akan memiliki kepercayaan yang tinggi dalam memasarkan hotelnya melalui Agoda. Kemudian, dari segi segmen marketing, Agoda sangat lekat dengan generasi milenial dalam pemenuhan kebutuhan akomodasi. Namun menarik untuk diteliti lebih lanjut tujuan dari pemesanan akomodasi ini, apakah untuk kebutuhan berwisata atau konsep liburan lain seperti yang mulai digemari saat ini yang disebut dengan istilah "staycation".

\section{DAFTAR PUSTAKA}

Ali, J. A., \& Howaidee, M. (2012). The impact of service quality on tourist satisfaction in Jerash. Interdisciplinary Journal of Contemporary Research in Business, 3(12), 164-187.

Chang, J. C. (2008). Tourists' satisfaction judgments: An investigation of emotion, equity, and attribution. Journal of Hospitality \& Tourism Research, 32(1), 108-134.

Cox, J., \& Dale, B. G. (2001). Service quality and e-commerce: An exploratory analysis. Managing Service Quality: An International Journal.

Damanik, D., Wachyuni, S. S., Wiweka, K., \& Setiawan, A. (2019). The Influence of Social Media on the Domestic Tourist's Travel Motivation Case Study: Kota Tua Jakarta, Indonesia. Current Journal of Applied Science and Technology, 1-14. https://doi.org/10.9734/cjast/2019/v36i630263

Dedeke, A. N. (2016). Travel web-site design: Information task-fit, service quality and purchase intention. Tourism Management, 54, 541-554.

Dewanti, R., Masruroh, M., \& Doni, B. (2007). Analisis Brand Equity Bina Nusantara University di Lingkungan SMU Jakarta. The Winners, 8(2), 197-213.

Dou, W., Lim, K. H., Su, C., Zhou, N., \& Cui, N. (2010). Brand positioning strategy using search engine marketing. Mis Quarterly, 261-279.
Hair Jr, J. F., Hult, G. T. M., Ringle, C., \& Sarstedt, M. (2016). A primer on partial least squares structural equation modeling (PLS-SEM). Sage publications.

Hariyani, R., \& Sartana, B. T. (2014). Pengaruh Brand Image, Lokasi, Dan Fasilitas Pendidikan Terhadap Keputusan Calon Mahasiswa Untuk Berkuliah Di Universitas Dan Akademi Sekretari Budi Luhur Tahun Akademik 2014/2015. Jurnal Ekonomika Dan Manajemen, 3(2).

Hidayah, N. (2013). Analisis Jalur Brand Image Sebagai Anteseden Loyalitas:(Studi Pada Program Pascasarjana Universitas Terbuka). Jurnal Pendidikan Dan Kebudayaan, 19(1), 1-17.

Ho, C.-I., \& Lee, Y.-L. (2007). The development of an e-travel service quality scale. Tourism Management, 28(6), 1434-1449.

Jalilvand, M. R., \& Samiei, N. (2012). The effect of word of mouth on inbound tourists' decision for traveling to Islamic destinations (the case of Isfahan as a tourist destination in Iran). Journal of Islamic Marketing.

Kotler, P., \& Keller, K. L. (2009). Manajemen Pemasaran (Marketing Management). Jilid I. Edisi $\mathrm{Ke}, 13$.

Kusmayadi, Wiweka, K., Parantika, A., Wahyuni, N., \& Adnyana, P.P. (2019). A Time Series Analysis of Airline Pricing Behavior Case Study Jakarta (CGK) - Denpasar (DPS) Market. Journal of Economics, Management and Trade, 1-10. https://doi.org/10.9734/jemt/2019/v22i630105

Kusumaningrum, D. A., Wachyuni, S. S., Ritasari, R., Kusumaningsih, R., \& Sahid, P. (2019). PENGARUH CUSTOMER SATISFACTION DAN BRAND IMAGE TERHADAP BRAND LOYALTY DI PANTAI SENTOSA RESTAURANT JAKARTA. Jurnal Sains Terapan Pariwisata, 4(1), 129-143. Lipiäinen, H. (2014). Digitization of the Communication and its Implications for Marketing. Jyväskylä Studies in Business and Economics, 152.

Lu, B., Fan, W., \& Zhou, M. (2016). Social presence, trust, and social commerce purchase intention: An empirical research. Computers in Human Behavior, 56, 225-237.

Mulhern, F. (2009). Integrated marketing communications: From media channels to digital connectivity. Journal of Marketing Communications, 15(2-3), 85-101. 
Ali, J. A., \& Howaidee, M. (2012). The impact of service quality on tourist satisfaction in Jerash. Interdisciplinary Journal of Contemporary Research in Business, 3(12), 164-187.

Chang, J. C. (2008). Tourists' satisfaction judgments: An investigation of emotion, equity, and attribution. Journal of Hospitality \& Tourism Research, 32(1), 108-134.

Cox, J., \& Dale, B. G. (2001). Service quality and e-commerce: An exploratory analysis. Managing Service Quality: An International Journal.

Damanik, D., Wachyuni, S. S., Wiweka, K., \& Setiawan, A. (2019). The Influence of Social Media on the Domestic Tourist's Travel Motivation Case Study: Kota Tua Jakarta, Indonesia. Current Journal of Applied Science and Technology, 1-14. https://doi.org/10.9734/cjast/2019/v36i630263

Dedeke, A. N. (2016). Travel web-site design: Information task-fit, service quality and purchase intention. Tourism Management, 54, 541-554.

Dewanti, R., Masruroh, M., \& Doni, B. (2007). Analisis Brand Equity Bina Nusantara University di Lingkungan SMU Jakarta. The Winners, 8(2), 197-213.

Dou, W., Lim, K. H., Su, C., Zhou, N., \& Cui, N. (2010). Brand positioning strategy using search engine marketing. Mis Quarterly, 261-279.

Hair Jr, J. F., Hult, G. T. M., Ringle, C., \& Sarstedt, M. (2016). A primer on partial least squares structural equation modeling (PLS-SEM). Sage publications.

Hariyani, R., \& Sartana, B. T. (2014). Pengaruh Brand Image, Lokasi, Dan Fasilitas Pendidikan Terhadap Keputusan Calon Mahasiswa Untuk Berkuliah Di Universitas Dan Akademi Sekretari Budi Luhur Tahun Akademik 2014/2015. Jurnal Ekonomika Dan Manajemen, 3(2).

Hidayah, N. (2013). Analisis Jalur Brand Image Sebagai Anteseden Loyalitas:(Studi Pada Program Pascasarjana Universitas Terbuka). Jurnal Pendidikan Dan Kebudayaan, 19(1), 1-17.

Ho, C.-I., \& Lee, Y.-L. (2007). The development of an e-travel service quality scale. Tourism Management, 28(6), 1434-1449.

Jalilvand, M. R., \& Samiei, N. (2012). The effect of word of mouth on inbound tourists' decision for traveling to Islamic destinations (the case of Isfahan as a tourist destination in Iran). Journal of Islamic Marketing.
Kotler, P., \& Keller, K. L. (2009). Manajemen Pemasaran (Marketing Management). Jilid I. Edisi Ke, 13.

Kusmayadi, Wiweka, K., Parantika, A., Wahyuni, N., \& Adnyana, P. P. (2019). A Time Series Analysis of Airline Pricing Behavior Case Study Jakarta (CGK) Denpasar (DPS) Market. Journal of Economics, Management and Trade, 1-10. https://doi.org/10.9734/jemt/2019/v22i630105

Kusumaningrum, D. A., Wachyuni, S. S., Ritasari, R., Kusumaningsih, R., \& Sahid, P. (2019). PENGARUH CUSTOMER SATISFACTION DAN BRAND IMAGE TERHADAP BRAND LOYALTY DI PANTAI SENTOSA RESTAURANT JAKARTA. Jurnal Sains Terapan Pariwisata, 4(1), 129-143.

Lipiäinen, H. (2014). Digitization of the Communication and its Implications for Marketing. Jyväskylä Studies in Business and Economics, 152.

Lu, B., Fan, W., \& Zhou, M. (2016). Social presence, trust, and social commerce purchase intention: An empirical research. Computers in Human Behavior, 56, 225-237.

Mulhern, F. (2009). Integrated marketing communications: From media channels to digital connectivity. Journal of Marketing Communications, 15(2-3), 85-101.

Nursanti, T. D., Masruroh, M., \& Adhikara, C. T. (2009). Kontribusi Brand Image Universitas Bina Nusantara terhadap Minat Sektor Industri Atas Alumni. The Winners, 10(1), 75-88.

Octavia, D., \& Tamerlane, A. (2017). The influence of website quality on online purchase intentions on Agoda. Com with e-trust as a mediator. Binus Business Review, 8(1), 9-14.

Oktavianus, E. (2014). PENGARUH HARGA E-COMMERCE ACCOUNT AGODA TERHADAP KEPUTUSAN MENGINAP TAMU DI SERELA HO TERIAU BANDUNG [PhD Thesis]. Universitas Pendidikan Indonesia. Phillips, W. J., Wolfe, K., Hodur, N., \& Leistritz, F. L. (2013). Tourist word of mouth and revisit intentions to rural tourism destinations: A case of North Dakota, USA. International Journal of Tourism Research, 15(1), 93-104. 
Pitchayadejanant, K., Chewwasung, K., Nakpathom, P., Srikasem, K., Lekmeechai, M., Chaiyawet, C., Suriwong, S., \& Tso, C. W. (2019). Determinants of E-service Quality Towards Continuing Using Mobile Application for Hotel Reservation: Case of Agoda Application. Tourism Proceeding, 218-225.

Prayag, G., Hosany, S., Muskat, B., \& Del Chiappa, G. (2017). Understanding the relationships between tourists' emotional experiences, perceived overall image, satisfaction, and intention to recommend. Journal of Travel Research, 56(1), 41-54.

Rakić, B., \& Rakić, M. (2014). Integrated marketing communications paradigm in digital environment: The five pillars of integration. Megatrend Revija, 11(1), 187-204.

Setiawan, B., Trisdyani, N. L. P., Adnyana, P. P., Adnyana, I. N., Wiweka, K., \& Wulandani, H. R. (2018). The Profile and Behaviour of 'Digital Tourists' When Making Decisions Concerning Travelling Case Study: Generation $\mathrm{Z}$ in South Jakarta. Advances in Research, 113. https://doi.org/10.9734/AIR/2018/43872

Sindunata, I., \& Wahyudi, B. A. (2018). PENGARUH e-WOM (ELECTRONIC-WORDOF-MOUTH) TERHADAP KEPUTUSAN PEMBELIAN DI agoda. Com. Jurnal Hospitality Dan Manajemen Jasa, 6(1).

Sugiyono. (2003). Download Sugiyono. 2003. Metode Penelitian Bisnis. Bandung. Pusat
Bahasa Depdiknas | Download Contoh Skripsi Regresi. Download Sugiyono. 2003. Metode Penelitian Bisnis. Bandung. Pusat Bahasa Depdiknas | Download Contoh Skripsi Regresi. http://downloadcontohskripsiregresi.blogsp ot.com/2018/11/download-sugiyono-2003metode.html

Sunyoto, D. (2013). Teori, kuesioner \& analisis data untuk pemasaran dan perilaku konsumen. Yogyakarta: Graha Ilmu.

Top Brand Index Beserta Kategori Lengkap | Top Brand Award. (n.d.). Retrieved March 19, 2020, from https://www.topbrand-award.com/ top-brand-index/

Wachyuni, S. S. (2019). The Effects of Service Quality, Customer Perceived Value, and Customer Satisfaction Towards Customer Loyalty of DAMRI Tour Bus. Journal of Business on Hospitality and Tourism, 5(2), 129-142.

Wachyuni, S. S., Wiweka, K., \& Liman, M. (2018). PENGARUH ONLINE DISTRIBUTION CHANNELS (ODS) TERHADAP HOTEL REVENUE. Journal of Tourism and Economic, 1(2), Article 2. https://doi.org/10.36594/jtec.v1i2.29 Wiweka, K., Wachyuni, S. S., Simawang, S. P., Adnyana, P., \& Wihartaty, E. (2019). Current Issues of Backpacking Tourism Development: Profile and Characteristics of "Sharecost" and "Opentrip" Tourist. Journal of Education, Society and Behavioural Science, 1-12. https://doi.org/10.9734/jesbs/2019/v30i230124 